\title{
Hygrothermal Effects on Dynamic Mechanical Analysis and Fracture Behavior of Polymeric Composites
}

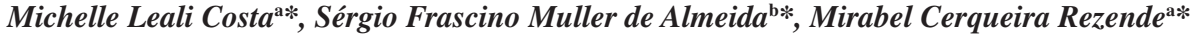 \\ aDivisão de Materiais, Instituto de Aeronáutica e Espaço, Centro Técnico Aeroespacial, \\ Praça Marechal do Ar Eduardo Gomes, $n^{\circ}$ 50, Vila das Acácias, \\ 12228-904 São José dos Campos - SP, Brazil \\ ${ }^{\mathrm{b}}$ Departamento de Engenharia Aeronáutica e Mecânica, Instituto Tecnológico de Aeronáutica, \\ São José dos Campos - SP, Brazil
}

Received: December 15, 2004; Revised: April 6, 2005

\begin{abstract}
Polymer composites used above their glass transition temperatures $T g$ present a substantial degradation of physical properties; therefore a material's glass transition temperature and its change with moisture absorption are of practical importance. Little attention has been paid to the role of the adhesive bonding between the reinforcing fiber and matrix, particularly for BMI matrix. In this work the effect of moisture on the dynamic mechanical behavior and the fiber/matrix interface was investigated. Two systems were evaluated: carbon fabric/epoxy and carbon fabric/bismaleimide laminates. The results demonstrated that the moisture absorbed by the laminates causes either reversible or irreversible plasticization of the matrix. The humidity combined with the temperature effects may cause significant changes in the $T g$ matrix and toughness affecting the laminate strength. Moisture absorption was correlated to the fracture mode of the laminate demonstrating the deleterious effect of moisture on the interface. This leads to debonding between fiber and matrix. This behavior was investigated by scanning electron microscopy and dynamic mechanical analysis.
\end{abstract}

Keywords: polymeric composites, dynamic mechanical properties, glass transition temperature, interface

\section{Introduction}

Polymer matrix composite materials used in structural parts of aircraft or other artifacts when in service may be exposed to environments involving usually temperature and humidity. Over the past few years, a great deal of experimental evidences have been accumulated to demonstrate that both physical and mechanical properties of composite materials can be strongly affected during hygrothermal ageing, affecting the composite performance ${ }^{1}$.

The measurement of the glass transition temperature $(\mathrm{Tg})$ of thermoset matrix in composites is very important because it defines the critical service temperature of the component and consequently their applications and engineering design parameters. For practical applications, epoxy and bismaleimide resins are normally used at temperatures below their $T g$, i.e., in the glass state. When the material is exposed to a hygrothermal environment, the $T g$ usually decreases and, therefore, the service temperature of the material changes. This modification of $T g$ reflects on the resin plasticization and on the water/resin interactions into the composite material. By identifying the mechanism responsible for the $T g$ changes it is possible to predict the decrease in $T g$ under environmental conditions ${ }^{2}$.

The presence of moisture within a polymer composite can lead to significant changes of the chemical and physical characteristics of the polymeric matrix. Two possible mechanisms have been suggested to explain the effects of moisture on most composite systems: matrix plasticization and degradation of the fiber/matrix interface ${ }^{3-10}$. Moisture absorption by epoxy matrix composites has a plasticizer effect, as evidenced by the $T g$ reduction of the matrix. This effect is usually reversible when the water is removed, but exposition to moisture at elevated temperatures can produce irreversible effects, which can be attributed to the chemical degradation of the matrix and to the attack on the fiber/resin interface. This causes an increase of the internal voids of the entangling polymer chain, promoting as a consequence the chain expansion and the microcracks formation into the polymer matrix ${ }^{4}$.

The way in which composite materials absorb moisture depends upon factors such as temperature, fiber volume fraction, reinforcement orientation, fiber nature (that is, permeability, polarity, density), area of exposed surfaces, diffusivity, and surface protection ${ }^{11-13}$. Moisture penetration into the composite materials is conducted by one major mechanism, namely, diffusion ${ }^{14}$. This mechanism involves the direct diffusion of water into the matrix and in a much less extent into the fibers. The other common mechanisms are capillarity and transport through microcracks and voids. The capillarity mechanism involves the flow of water molecules along the fiber/matrix interface, followed by diffusion from the interface into the bulk resin. Transport of moisture by microcracks and voids involves both flow and storage of water into the microcracks and other forms of microdamages ${ }^{4}$.

The strength of the interface determines how much of the applied stress can be transferred to the load-bearing fibers. This strength is largely determined by the contact area between fibers and matrix and the level of adhesion at the contact points. However, it is not clear how the interface should be tailored to optimize composite properties and whether optimum adhesion is desirable or essential to achieve the best balance of mechanical properties s, $^{1,6,13,18}$.

Although many investigators have studied epoxy systems reinforced with various types of fibers and fillers ${ }^{1-18}$, little attention has been paid to the adhesive bonding between the reinforcing fiber and matrix, particularly for BMI matrix. To the best of the authors knowledge this study is not available in the open literature for BMI matrices. 
The adhesive bonding between fiber and matrix is very important as it controls the interface profile in terms of voids and pores, which can greatly affect the absorption according to the mechanisms previously discussed. Moreover, a wide scatter of $T g$ values for a given epoxy and bismaleimide systems is reported in literature ${ }^{7-10}$. Frequently, the variation in $T g$ is explained by differences associated with the material preparation. However, from experimental data of the literature and from results of this study, the effects of hygrothermal history (i.e. exposure to moisture and temperature) on $T g$ are also quite significant.

This work presents the dynamic mechanical behavior of two types of composites manufactured with either prepregs of carbon fiber fabric/epoxy or carbon fiber fabric/bismaleimide. Moisture absorption was correlated to the fracture mode of the laminate demonstrating the deleterious effect of moisture on the interface. This leads to debonding between fiber and matrix. This behavior was investigated by scanning electron microscopy and dynamic mechanical analysis.

\section{Experimental}

\subsection{Dynamic mechanical analysis (DMA)}

Two types of composite laminates were studied in this work: carbon fabric reinforced epoxy (F584) and carbon fabric reinforced bismaleimide (BMI - F652). T300 fibers were used for both sets of laminates. All laminates were produced with eight harness satin weave preimpregnated fabric supplied by Hexcel Composites. All specimens were cured in an autoclave at $180^{\circ} \mathrm{C}$ with pressure of $0.71 \mathrm{MPa}$. The BMI specimens were post cured for 8 hours at $232^{\circ} \mathrm{C}$.

The dynamic mechanical behavior of the specimens was evaluated by a Thermal Analyzer TA2100 of TA Instruments, with DMA983 modulus operating in the three-point bending horizontal measuring system. The DMA equipment was calibrated using indium standard. The experimental conditions used were: dynamic force $(0.7 \mathrm{Nm})$; oscillation displacement $(0.20 \mathrm{~mm}), 1 \mathrm{~Hz}$ frequency, heating rate $\left(3.0^{\circ} \mathrm{C} / \mathrm{min}\right)$ and temperature range of $30-300^{\circ} \mathrm{C}$. Before starting each experiment, the equipment was stabilized at $30^{\circ} \mathrm{C}$ by $3 \mathrm{~min}$.

\subsection{Moisture absorption}

The moisture absorption of carbon/epoxy laminates with different levels of porosity was measured according to procedure B of ASTM D 5229/D5229 M-92. In this study the moisture absorption was monitored placing the samples for a long specified time in a humidity-controlled chamber (Heraeus Vötsch model VUK08/1000) at $80{ }^{\circ} \mathrm{C}$ and $95 \%$ relative humidity $(\mathrm{RH})$. All samples were cut in the dimensions of $24 \mathrm{~mm} \times 6 \mathrm{~mm} \times 2 \mathrm{~mm}$. Nine specimens of each laminate were submitted to hygrothermal conditioning in a climatic chamber. The size and weight of the specimens were measured as a function of time. All specimens were dried according of ASTM C562-85 before the hygrothermal conditioning. Every week, only the traveler samples were removed from the humidity-controlled chamber and weighted. Specimens were allowed to cool down for a short period of time before weighting. The effect of removing the specimens from the chamber for a short period of time on the measurement of weight gains was shown to be negligible. The specimen weight was measured using a scale with $0.1 \mathrm{mg}$ accuracy. This procedure was repeated for 9 weeks until reaching the limit of saturation (constant weight). Some specimens were removed before saturation to yield laminates with intermediate levels of moisture absorption.

The water gain percentage, $\mathrm{M} \%$, is determined from:

$$
M \%=\left|\frac{M u-M d}{M d}\right| x 100
$$

where:

- $\mathrm{Mu}$ - is the wet weight of specimen (water-absorbed matrix) (g); and

- Md - is the initial weight of dry specimen, (g).

\subsection{Microstructural analysis}

Scanning electron microscopy (SEM) was employed to characterize the fracture surfaces of dried and wet specimens of carbon/epoxy and carbon/bismaleimide laminates submitted to the interlaminar shear and compressive tests as described in $\mathrm{Costa}^{14}$. The distribution, shape and location of voids and fiber/matrix interface in the carbon/ epoxy and carbon/BMI samples before and after mechanical tests was examined, using a LEO 435VPI Microscope with vacuum level control. No metallic coating was necessary on the samples.

\section{Results}

\subsection{Dynamic mechanical analysis}

Figures 1 and 2 show the curves of dynamic mechanical analysis that present similar behavior with differences in the magnitude of

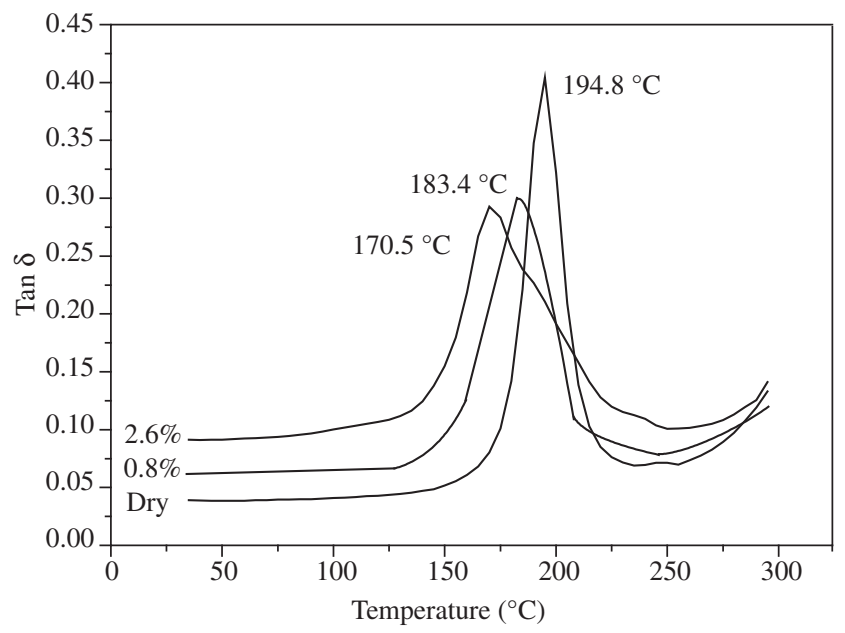

Figure 1. Tan delta $(\delta)$ as function of temperature of dry and wet carbon/ epoxy laminates.

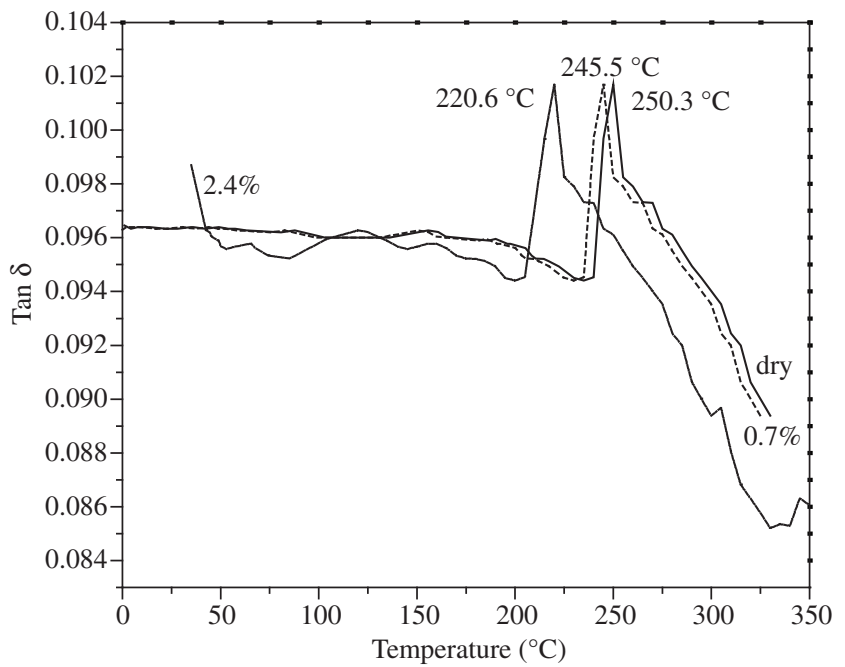

Figure 2. Tan delta $(\delta)$ as function of temperature of dry and wet carbon/bismaleimide laminates. 
$\tan$ delta $(\delta)$ values, that depend on the polymeric matrix and the moisture sorbed during the hygrothermal conditioning. As can be observed, the curves for carbon/BMI laminates versus temperature presented noise for high levels of moisture absorption. Therefore, the analysis of these data is limited to a qualitative comparison between the epoxy and BMI system behaviors.

The measurement of $T g$, among other reasons, presents scatter because the glass transition is actually a temperature range within large range molecular motion is activated by the temperature increase. In a dynamic mechanical experiment several characteristic temperatures in the transition region may be arbitrarily defined as $\operatorname{Tg}^{10,18-20}$. These include the onset temperature of the characteristic drop in modulus, the inflection temperature of the drop in modulus, the onset temperature of the characteristic damping peak and the temperature of maximum damping. The problem is more complex in the case of wet polymer samples with high $T g$ values, because the samples lose moisture to a significant extent in the glass transition region where the molecular mobility and the moisture diffusion are enhanced. Thus, probably there is a gradient of moisture concentration through the samples in the $T g$ region, and a corresponding distribution of temperature dependent of the molecular relaxation times ${ }^{14}$. For this reason, in the present work, it was chosen to assign $T g$ to the maximum peak of tan delta for all samples.

The $T g$ values determined for the carbon/epoxy and carbon/BMI samples are within the range described in the literature (Tg epoxy $\sim 180$ ${ }^{\circ} \mathrm{C}$ and $\left.\mathrm{Tg} B M I \sim 250{ }^{\circ} \mathrm{C}\right)^{9,19,21}$. It can be observed in Figure 1 and 2 that the samples submitted to the hygrothermal conditioning showed a reduction in $T g$. The curve shift increases with the increase of the moisture levels. For the carbon/BMI specimens, Figure 2, the $T g$ presents a small decrease for low levels of moisture absorption and a great decreases for high levels of moisture absorption.

The previous results demonstrate that the variation of $\mathrm{Tg}$ with moisture content are different for epoxy and BMI matrices. Clearly, the magnitude of the curve shift depends not only on the moisture content but also on the polymeric matrix. That is, the moisture level leads to different changes in $T g$ depending on the particular characteristics of molecular structures and matrix/fiber interface interactions of the matrix system.

The different behavior of the two polymeric matrices studied and changes in the distribution of relaxation times associated with the $\alpha$-transition $(\mathrm{Tg}$ ) could not have been caused only by the plasticization effect because the specimens were submitted to the same hygrothermal conditioning before the DMA tests. Other possible explanation for the change in the relaxation time distributions involves a specific evolution of the macromolecular network at the fiber/matrix interface and/or debonding during the hygrothermal conditioning. Although it is not possible to identify these processes from a chemical point of view, it is possible to conclude that these processes affect the interface sufficiently to modify the relaxation mechanisms associated with the $\alpha$-transition. The movement of the polymeric chain is more difficult for higher interface adhesion. Therefore, the interface adhesion increases the $T g$. Since the environmental conditioning reduces the $T g$, it is expected that the interface adhesion be also reduced. This hypothesis is corroborated by interlaminar shear strength measurements (an indirect measurement of interface adhesion) that decrease with moisture absorption (Figures 3 and 4).

The $T g$ differences between the epoxy and bismaleimide laminates can be also explained based on the nature of water interaction with both resins. According to Zhou and Lucas², water molecules diffuse into the material and effectively disturb the interchain bonding established by van der Waals forces and hydrogen bonds into the resins. This disturbance involving the link breaking of the chain network by the moisture is named Type I. The net effect of this interchain bond breakage is the increase of chain mobility that contributes to the $T g$ decrease. The moisture absorption increase associated with the interchain bond breakages results in a significant drop of the $T g$.

\subsection{Microscopic analysis}

The effect of the moisture content on the laminate strength was assessed by interlaminar shear strength (ILSS) measurements of the dry and hygrothermally conditioned carbon/epoxy and carbon/BMI specimens. Ten specimens of each type with dimensions $24 \mathrm{~mm} \times 6.35 \mathrm{~mm} \times 4.1 \mathrm{~mm}$ were tested according to ASTM Standard D2344.

Figures 3 and 4 are bar charts based on the ILSS data. These data also include results obtained in previous works for the same specimens with and without influence of the environmental condition ${ }^{14-17}$. The specimens subjected to environmental conditions are referred according to the percentage of absorption water by the samples.

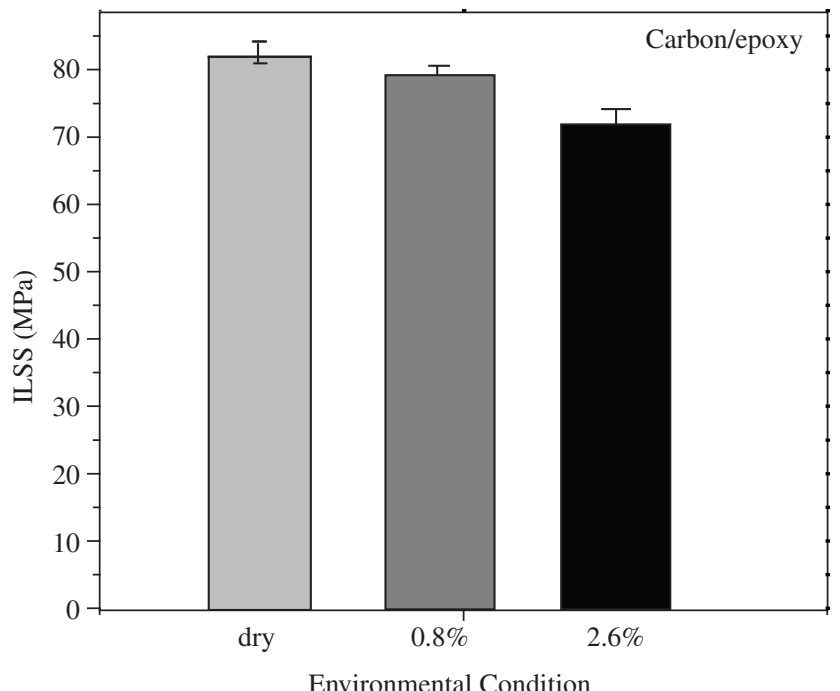

Figure 3. Variation of interlaminar shear strength as function of environmental conditioning of carbon fabric/epoxy laminates.

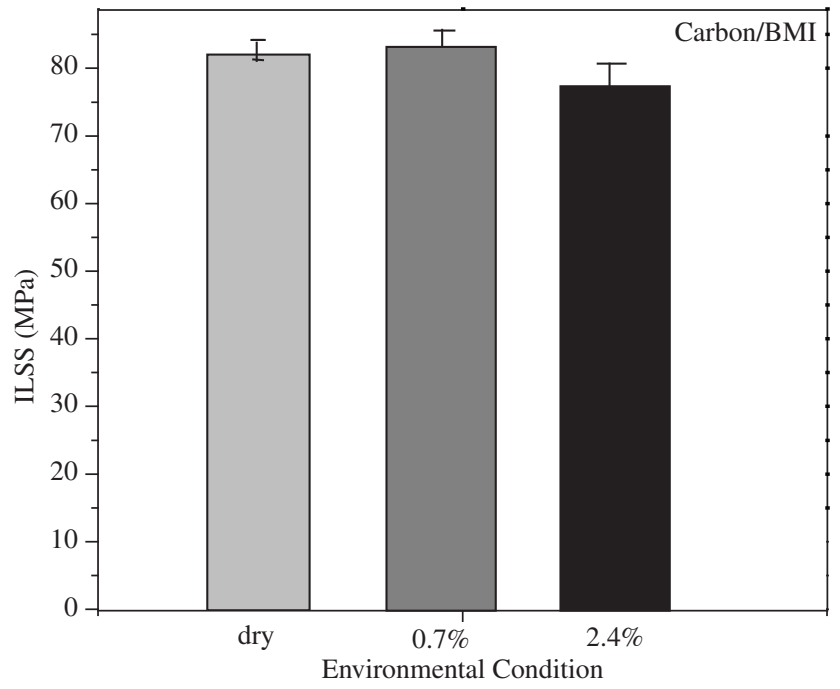

Figure 4. Variation of interlaminar shear strength as function of environmental conditioning of carbon fabric/BMI laminates. 
Figure 3 shows a decrease of $6.0 \%$ in the interlaminar shear strength for the carbon/epoxy laminates after the environmental conditioning. The water absorbed by the epoxy laminates, in general, causes reversible plasticization of the matrix and lowers its glass transition temperature. Combined with temperature effects, these factors cause significant changes in the matrix toughness affecting the laminate strength. Moreover, humidity and temperature cause dimensional changes and induce stresses in the laminate that degrade the fiber matrix interface.

It can be observed in Figure 4 that a small increase in the interlaminar shear strength of the carbon/bismaleimide laminates subjected to the environmental conditions occurs ( $0.7 \%$ of absorption water), but the scattering of results was greater. This increase in the mechanical strength of carbon/bismaleimide laminate may be related to the mechanism of water sorption by the composite and how the water molecules were bonded to the polymeric chain.

The effects of moisture on the fracture surfaces of the specimens were examined by scanning electron microscopy (SEM). Figure 5 presents a typical fracture surface of fractured interlaminar shear strength dry specimen of carbon/epoxy laminate. The smooth clean surface of fibers is caused by a fracture micromechanism involving an interfacial debonding in the carbon/epoxy fabric laminate. Cracks through a fiber tow (collection of fiber filaments - typically from 3000 to 12000 for carbon fiber), either in the warp or fill direction, can also be identified as a fracture micromechanism in Figure 5. The crack runs along the matrix between fibers. This feature suggests a brittle fracture micromechanism. In this material (carbon/epoxy), the microcracks initiated at the matrix at the fiber/matrix interface, growing under the action of shear loads along planes parallel to the loading direction. The growth and coalescence of these microcracks can lead to a primary $\mathrm{crack}^{22}$.

Fracture surfaces of carbon/epoxy laminate conditioned at $80{ }^{\circ} \mathrm{C} / 95 \% \mathrm{RH}$, with $2.6 \%$ moisture content, showed a similar fracture micromechanism observed for the dry specimen. However, the moisture absorption induced an increase of the interfacial debonding area, as shown in Figure 6. The effect of debonding along the warp/fill yarn interface supersedes the effect of interfacial (fiber/matrix) debonding. Large debonding along resin rich areas resulted in significant decrease of the material toughness ${ }^{14,17}$.

Figures 7 and 8 present the major features that characterize the failure surface of dry carbon/BMI laminate. Figure 8 indicates interfacial debonding but it is also observed a large number of fibers coated with a thin layer of polymeric matrix caused by a relatively good fiber/resin adhesion as detailed in Figure 7.

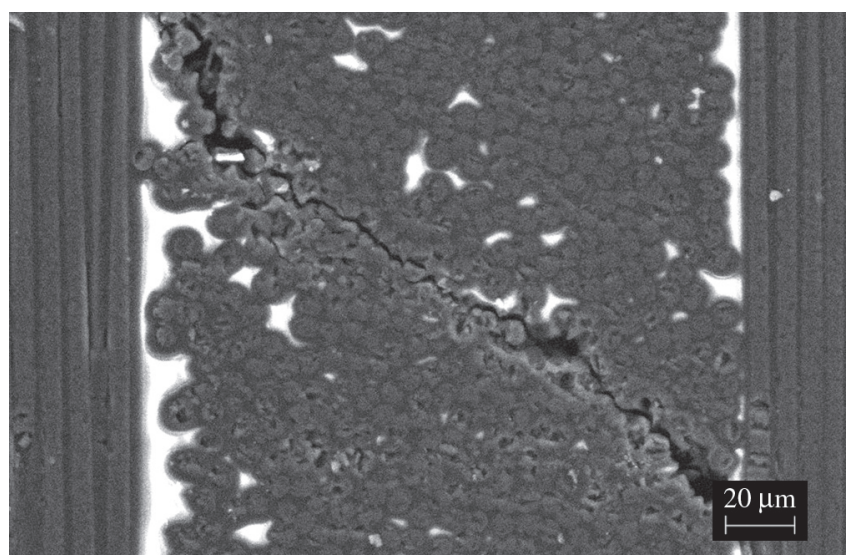

Figure 5. Fractograph of fiber/matrix interface of dry carbon/epoxy laminate.
Fracture surface of carbon/BMI specimens conditioned at $80{ }^{\circ} \mathrm{C} / 95 \% \mathrm{RH}$, with moisture content of $2.4 \%$ is depicted in Figure 9. Moisture absorption toughened the matrix leading to a slight increase in the fracture toughness of the laminate ${ }^{14,17}$. Large extents of debonded areas and resin microcracking were observed in fracture surfaces. This observation suggests that the water penetrated into the relatively large spaces in the matrix phase, such as pores, cracks and unbonded parts of the interfaces.
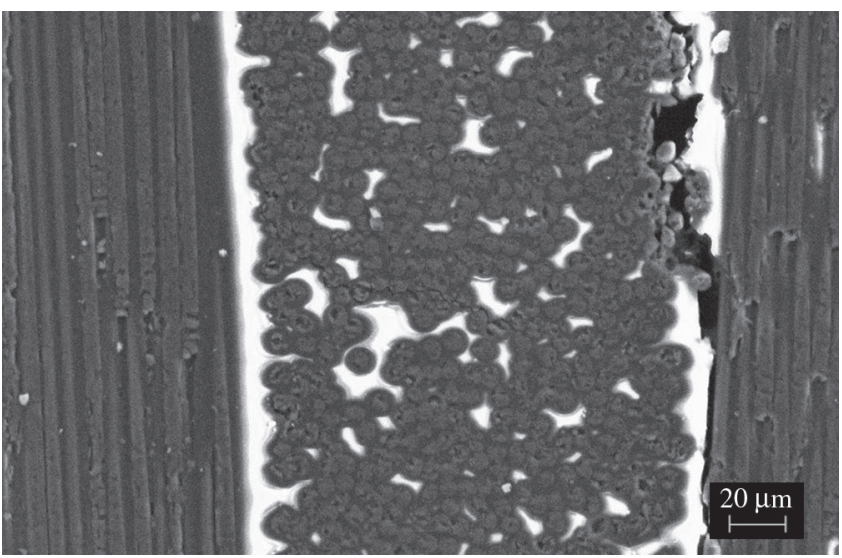

Figure 6. Fractograph of fiber/matrix interface of wet of carbon/epoxy fabric laminate $(2.6 \%$ of moisture).

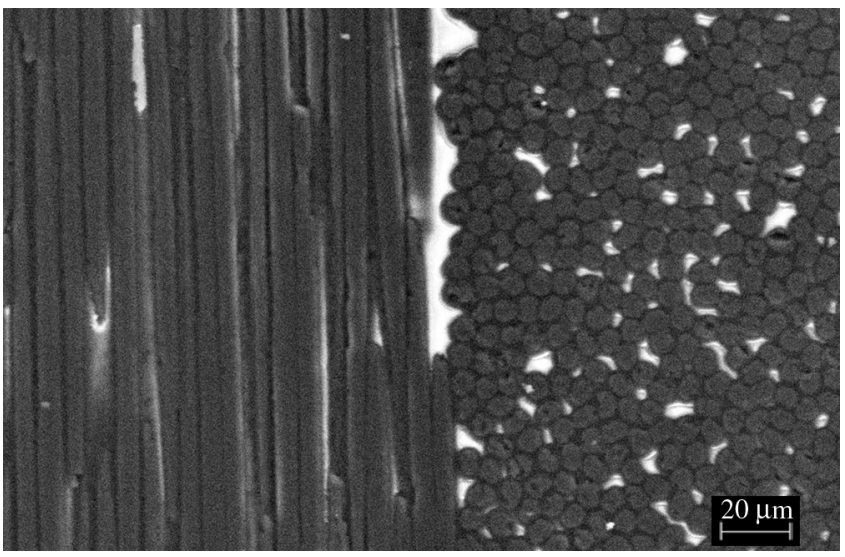

Figure 7. Micrograph of interface region of dry carbon/BMI fabric laminate.

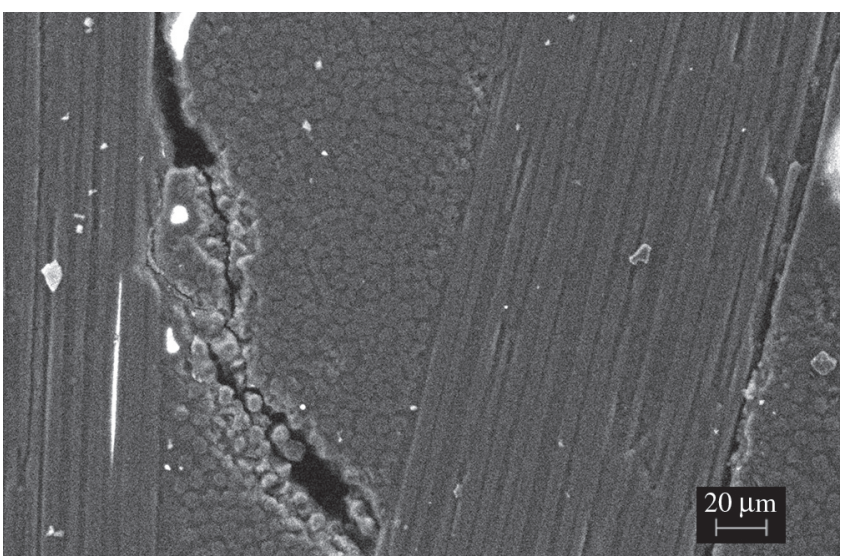

Figure 8. Fractograph of interface region of dry carbon/BMI fabric laminate. 
Moisture absorption can also induce swelling deformation. This phenomenon is almost linear with respect to the absorbed amount of moisture. When the specimens are removed from the environmental chamber in the beginning of the hygrothermal conditioning process and submitted to the ILSS test, the fibers provide some lateral restraint in the transverse direction of the polymer composite specimens, but they do not restrain the swelling of the matrix along the loading direction. This effect is reflected in very low longitudinal deformation in the polymer composite specimens. This restraining effect is necessarily offset by internal stresses within the matrix phase (mainly compression) and along the fiber/matrix interfaces (shear) ${ }^{23}$. Quantitative analysis of these stresses is outside the scope of the present study and was treated in Costa ${ }^{14}$.

Moisture penetration through the fiber/matrix interfaces causes also interfacial debonds causing the rupture or degradation of the interface, exposing the carbon fibers, as depicted in Figure 10. The absorption of the water molecules accelerated by temperature used in the hygrothermal conditioning weakens the fiber/matrix interface exposing the fibers.

It has been shown that the sorbed moisture acts as a plasticizer and a crazing agents into the thermoset resins ${ }^{1-13}$. Absorption of moisture induces also swelling of the matrix. Because the swollen matrix forms a shell around the dry matrix, the dry matrix will be placed under a state of triaxial stresses. When the swelling stresses reach a

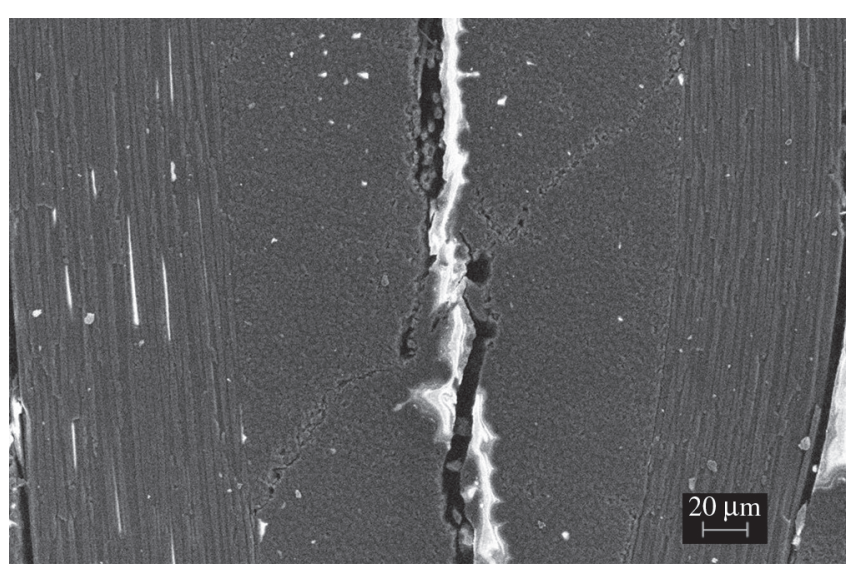

Figure 9. Fractograph of interface region of wet carbon/BMI fabric laminate (2.4\% of moisture).

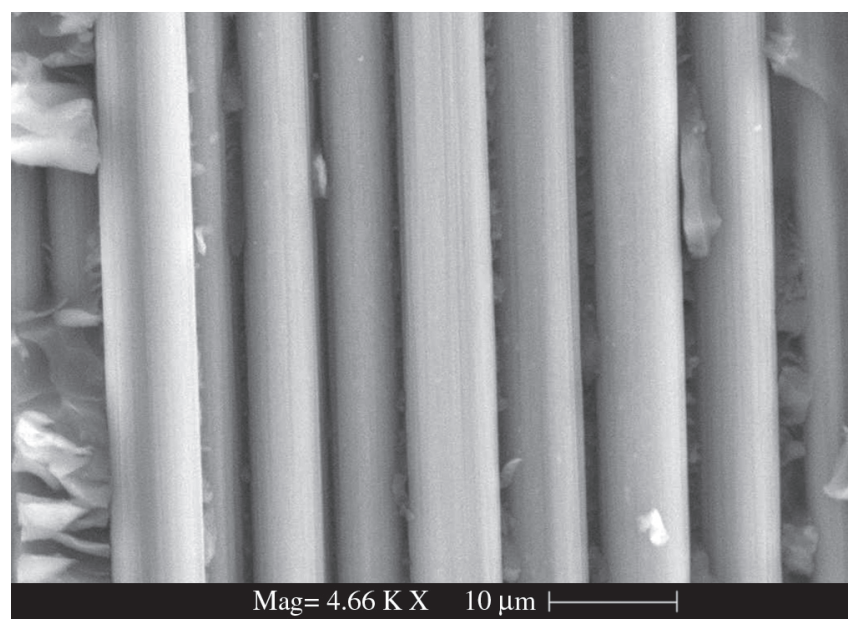

Figure 10. Micrograph of longitudinal fracture of wet carbon/epoxy $(2.6 \%$ of moisture). critical value, the fracture of the matrix occurs. This mechanism can lead to the rupture of the fiber/matrix interface. Knowledge of the mechanisms that drive moisture sorption, as well as the influence of sample dimensions, temperature, and relative humidity, becomes crucial when long-term properties of the material are needed.

\section{Conclusions}

The $T g$ values determined for the carbon/epoxy and carbon/BMI samples are within the range described in the literature. It can be observed that the samples submitted to the hygrothermal conditioning presented a reduction in $T g$ that increases with the increase of the moisture levels. It was also observed that the magnitude of this effect is dependent on the polymeric matrix. That is, the moisture level leads to different changes in $T g$ that depend on the particular characteristics of molecular structures and matrix/fiber interface interactions of the matrix system. This study demonstrated that absorbed water in an epoxy and bismaleimide resins lowered the $T g$ by as much as $24^{\circ} \mathrm{C}$.

It is also observed by SEM that the moisture penetration along the fiber/matrix interfaces causes interfacial debonds leading to the rupture or degradation of the interface. The absorption of moisture accelerated by temperature used in the hygrothermal conditioning weakens the fiber/matrix interface exposing the carbon fibers.

\section{Acknowledgments}

The authors thank FAPESP (process n ${ }^{\circ}$ 98/10079-1 and 02/018087) and CNPq (process n ${ }^{\circ} 300599 / 96 ; 300219 / 90-3$ and 302112/20030 ) for the financial support, the Hexcel Composites and EMBRAER for helping in the laminates production.

\section{References}

1. Chateauminois A, Vicent L, Chabert B, Soulier JP. Study of the interfacial degradation of a glass-epoxy composite during hygrothermal ageing using water diffusion measurements and dynamic mechanical thermal analysis. Polymer. 1994; Oct; 35(22): 4766-74.

2. Zhou J, Lucas JP. Hygrothermal effects of epoxy resin. Part I: the nature of water in epoxy. Polymer. 1999; Sept; 40(20): 5513-22.

3. Núñez L, Villanueva M, Fraga F, Núñez MR. Influence of water absorption on the mechanical properties of a DGEBA $(\mathrm{n}=0) / 1,2 \mathrm{DCH}$ epoxy system. Journal of Applied Polymer Science.1999; Oct 10; 74(2): 353-58.

4. Andreopoulos AG, Tarantili PA. Water sorption characteristics of epoxy resin-UHMPE fibers composites. Journal of Applied Polymer Science. 1998; Oct 24, 70(4): 747-55

5. Shen CH, Springer GS. Moisture absorption and desorption of composite materials. In: Springer GS, editor. Environmental effects on composite materials. Westport, CT: Technomic; 1981. chapter 3.

6. Shen $\mathrm{CH}$, Springer GS. Environmental effects on the elastic modulus of composite materials. In: Springer GS, editor. Environmental effects on composite materials. Westport, CT: Technomic; 1981. chapter 7.

7. De'Nève B, Shanahan MER. Water absorption by an epoxy resin and its effect on the mechanical properties and infra-red spectra. Polymer. 1993; Dec, 34(24): 5099-105.

8. Hancox NL, Mayer RM. Design data for reinforced plastics. 4th ed. London: Chapman \& Hall; 1994.

9. Hexcel Composites. Resin systems for advanced composites. Pleasanton, CA: Hexcel Composites, 1996.

10. Lee SM. International encyclopedia of composites. 2nd ed. New York: VCH Publishers; 1991

11. Thomason JL. The interface region in glass fibre-reinforced epoxy resin composites: 1. Sample preparation, void content and interfacial strength. Composites. 1995; Jul; 26(7): 467-75. 
12. Thomason JL. The interface region in glass fibre-reinforced epoxy resin composites: 2. Water absorption, voids and the interface. Composites. 1995; Jul; 26(7): 477-85.

13. Thomason JL. The interface region in glass fibre-reinforced epoxy resin composites: 3. Characterization of fibre surface coatings and the interphase. Composites. 1995; Jul; 26(7): 487-98.

14. Costa ML. Effect of void content on the mechanical properties on the carbon fiber/epoxy and carbon fiber/bismaleimide advanced composites [PhD thesis]. Instituto Tecnológico de Aeronáutica: ITA, São José dos Campos, SP, Brazil, 2002.

15. Costa ML, Rezende MC, Almeida SFM. Critical Void Content for Polymer Composites Laminates. AIAA Journal. In press; 2005.

16. Costa ML, Rezende MC, Almeida SFM. The influence of porosity on the interlaminar shear strength of carbon/epoxy and carbon/bismaleimide fabric laminates. Journal of Composite Science and Technology. 2001; Nov; 61(14): 2101-08.

17. Costa ML, Rezende MC, Almeida SFM. Strength of Hygrothermally Conditioned Polymer Composites with voids. Journal of Composite Materials. In press; 2005.

18. Barton JM, Greenfield DCL. British Polymer Journal. 1986; 18(1): 51-5.

19. Delaware Composite Design Encyclopedia. Processing And Fabrication Technology. USA:Technomic Publishing Co. Inc; 1990.

20. Schwartz MM. Composite Materials - Properties, Nondestructive Testing and Repair, New Jersey: Prentice Hall Inc; 1997.

21. Boyd J. SAMPE Journal 1999. 35(6): 13-22.

22. Zhao S, Gaedke M. Advanced Composite Materials. 1996. 5(4): 291-307.

23. Ishai O. Polymer Engineering and Science.1975.15(7): 491-99. 